\title{
Impact on cardiac surgery volume of a comprehensive partnership with Integrated Health Solutions
}

\author{
Amy Watling, MBA \\ Janine Doucet, RN \\ Morteza Zohrabi, MD \\ John Fedirko, RRT \\ Ansar Hassan, MD \\ Sohrab Lutchmedial, MD \\ Jeffrey MacLeod, BSc \\ Zlatko Pozeg, MD \\ Craig Brown, MD \\ Jean-Francois Légaré, MD
}

Accepted Nov. 12, 2019

\section{Correspondence to:}

J.F. Légaré

New Brunswick Heart Centre

400 University Ave

PO Box 2100

Saint John NB E2L 4L2

legarej@me.com

DOI: $10.1503 /$ cjs.007519
Background: The New Brunswick Heart Centre (NBHC) entered a contractual partnership with Integrated Health Solutions (IHS) to help address increasing wait times in the province of New Brunswick.

Methods: Team leaders were identified from each of the target areas, including surgeons, anesthesiologists, nurses (operating room, intensive care unit [ICU] and postoperative ward), access coordinators and administrators. The methodology used was based on Lean principles and involved exercises by stakeholders aimed at identifying opportunities for improvement. A weekly dashboard was created to monitor and facilitate improvement efforts. No additional hospital beds or operating room theatres were added during the study period.

Results: After 2 years, the annual number of cardiac surgical interventions increased from 788 to 873 , representing a $10.8 \%$ increase in capacity. The best median wait time for patients decreased from 52 to 35 days (35\% reduction). The best 90 th percentile wait time decreased from 126 to 98 days (22\% reduction). The overall increase in capacity could be explained in part by the significant increase in fast tracking from the ICU to the ward (> 2-fold) or bypassing the ICU altogether (4-fold increase reaching $13 \%)$. Despite these successes, challenges persist as the number of OR cancellations remained around $7.5 \%$ of all cases, mainly because of limited ICU resources.

Conclusion: The NBHC-IHS partnership on this project has resulted in excellent engagement by stakeholders and promoted team cohesiveness. Furthermore, it has allowed significant reorganization and realignment of efforts to limit wait times and maximize overall capacity.

Contexte : Le New-Brunswick Heart Centre (NBHC) a conclu une entente contractuelle avec Integrated Health Solutions (IHS) pour remédier aux temps d'attente de plus en plus longs au Nouveau-Brunswick.

Méthodes : Des chefs d'équipe ont été identifiés pour chaque domaine cible, notamment la chirurgie, l'anesthésie, les soins infirmiers (en salle d'opération, aux soins intensifs et en soins postopératoires), la coordination des soins et la direction. La méthodologie utilisée se fondait sur l'approche Lean et comprenait des exercices visant à relever les possibilités d'amélioration. Un tableau de bord hebdomadaire a été créé pour suivre et faciliter les mesures d'amélioration. On n'a ajouté aucun lit d'hôpital et aucune salle d'opération pendant la période étudiée.

Résultats : Après 2 ans, le nombre de chirurgies cardiaques par année est passé de 788 à 873 , une augmentation de $10,8 \%$ de la capacité. Le temps d'attente médian pour les patients est tombé de 52 à 35 jours (réduction de $35 \%$ ). Le temps d'attente au $90^{\mathrm{e}}$ centile est passé de 126 à 98 jours (réduction de $22 \%$ ). L'augmentation générale de la capacité peut s'expliquer en partie par la réduction significative du temps passé aux soins intensifs avant l'admission en soins généraux ( $>2$ fois) ou par l'élimination complète du passage aux soins intensifs (augmentation de 400\%; $13 \%$ des cas). Malgré ces réussites, des défis demeurent puisque le taux d'annulation des interventions est resté autour de 7,5\% des cas, surtout en raison des ressources limitées aux soins intensifs.

Conclusion : Le partenariat NBHC-IHS sur ce projet a permis de mobiliser efficacement les participants et a favorisé la cohésion au sein de l'équipe. Il a en outre permis une importante réorganisation des ressources pour réduire les temps d'attente et augmenter la capacité générale. 
U niversal health care in Canada has been in place since 1984 with the enactment of the Canada Health Act. Unfortunately, health care costs have been rising year over year and now represent $11.3 \%$ of the Canadian gross domestic product, despite government efforts to reduce expenditures. ${ }^{1}$ The reasons for the rise in health care costs are multifactorial, but they are in part related not only to the actual costs of care delivery, but also to an aging population that uses more health care resources. ${ }^{2}$

This means that budgetary pressures are substantial for most jurisdictions in Canada, requiring decision-makers to ration some services in the face of rising demands. ${ }^{3,4}$ This is particularly true with expensive interventions such as cardiac surgery where new technologies can add to the overall economic pressures. For those delivering cardiac surgery care in the Canadian health care system, there is therefore constant pressure to find novel approaches to improve performance to meet the rising demands on the system without increasing costs.

In New Brunswick, the New Brunswick Heart Centre (NBHC) is the only tertiary cardiac centre responsible for invasive cardiac care, including cardiac surgery, in the province. Like most health care centres in Canada, the $\mathrm{NBHC}$ has faced limited resources. Specifically, in the face of increasing demands for cardiac surgery care, there has been no change in the number of operating rooms (ORs) or intensive care beds, ultimately resulting in the need for managed wait lists for patients requiring cardiac surgery. Patients are currently triaged on the basis of urgency; some are forced to wait until their procedure can be accommodated. Despite efforts to manage wait lists and minimize waiting, it is not uncommon for patients to wait longer than the benchmarks established by the Canadian Cardiovascular Society. 5,6 At the NBHC the number of patients waiting for cardiac surgery reached critical levels in 2016, when some patients were waiting a median of more than 200 days for lifesaving surgery and only $25 \%$ had their procedure within standard wait times.

In the present paper we outline the approach taken at the NBHC with the help of Integrated Health Solutions (IHS) to tackle this wait time challenge and improve the efficiency of clinical care delivery. Partnership with industry in this context remains rare in Canada; to our knowledge, our experience is unique in the Canadian health care system. We report here the result of our collaboration with IHS, which is a division of Medtronic, on cardiac surgical capacity. The approach used was based on Lean methodology, which aims to improve quality by reducing waste and improving flow. 7,8 This type of approach has been adopted by many health care systems in an attempt to address process of care and efficiency. ${ }^{9-11}$ In the present study, we specifically look at 2 consecutive fiscal years at the NBHC and compare those with the previous years in terms of cardiac surgical case volume, efficiency and wait times in New Brunswick.

\section{Methods}

\section{Setting}

The NBHC is the sole cardiac surgery program in the province of New Brunswick, which has a population of around 750000 people. The NBHC has been in place since 1991, and it has seen a gradual growth in cardiac surgery volume that has mirrored the province's population demographics. During the present study, all patients received what was felt to be the standard of care. For the purposes of the study, cardiac surgical volume included both open cardiac surgical cases and transcatheter aortic valve implantation (TAVI), given the utilization of cardiac surgical resources. During the 2-year window in which the study was conducted, the following resources remained constant: 2 ORs were used per day, there were 4 dedicated surgical intensive care unit (SICU) beds (with the ability to borrow beds from the general ICU) and there was a 4-bed step-down unit within a total of 23 cardiac surgery beds. Similarly, during the study period, 5 cardiac surgeons were responsible for clinical care delivery with the assistance of 6 nurse associates because the NBHC does not have residents or fellows. Standard admission and postoperative orders sets were in place to help manage all patients, with small variations between surgeons based on personal preferences, as previously described. ${ }^{2}$

\section{Initiation of collaboration with Integrated Health Solutions}

Discussions between clinicians at the NBHC and Horizon Health Network, where the NBHC is housed, took place in an effort to seek solutions to address the unacceptably long wait times experienced by patients. It was believed that process improvement could address, at least in part, some of the wait time issues without adding resources to the delivery of cardiac surgery care. In the present paper we focus exclusively on the implementation of the IHS partnership with the Division of Cardiac Surgery, which began in the summer of 2016. In brief, the process included a complete review of all of the components and processes of care of the Division of Cardiac Surgery. As part of this process, team leaders were identified from each of the target areas, including surgeons, anesthesiologists, nurses (OR, ICU and postoperative ward), access coordinators and administrators. The methodology used was based on Kaizen principles, which advocates for the participation of all team members in discussions to identify solutions, with the support and mentorship of representatives from IHS. ${ }^{7,8}$

\section{Baseline assessment and development of improvement action plan}

In the beginning of the engagement, IHS consultants conducted a baseline assessment of the delivery of cardiac 
surgical care at the NBHC and measured baseline performance. The consultants further interviewed key stakeholders to better understand and pinpoint areas that needed improvement. The consultants worked with the steering committee (stakeholder representatives) to define departmental priorities. The steering committee focused on the return on investment (ROI) process, targeting desired outcomes that aligned with the priorities of stakeholders, including management. The IHS consultant team included several people, 2 of whom in particular had substantial expertise. The expertise included management experience in health care $(>30 \mathrm{yr}$ in cardiac catheterization laboratory, electrophysiology laboratory, noninvasive cardiology, interventional radiology, perfusion) and decades of experience implementing Lean Six Sigma projects with certification as a Lean Six Sigma Master Black Belt.

After the development of the plan, team leaders were identified from each of the target areas, including surgeons, anesthesiologists, nurses (OR, ICU and postoperative ward), access coordinators and administrators. Together, they developed a project charter and project ROI framework. The IHS consultants organized and led a 5-day Kaizen (rapid improvement) workshop. The workshop trained the team leaders on the foundational elements behind the Lean Six Sigma methodology and certified them with a Yellow Belt. During the workshop, the team leaders, led by IHS consultants, developed a roadmap for the future: a quality improvement action plan, a communication plan and a control plan. These plans were presented for approval to the steering committee after the Kaizen workshop.

\section{Implementation of process improvement projects}

After the approval of the improvement action plan, the team leaders started to implement the projects. Process improvement projects were identified and implemented by team leaders on a continuous basis, and monthly and quarterly reports were produced (Fig. 1). IHS assigned a

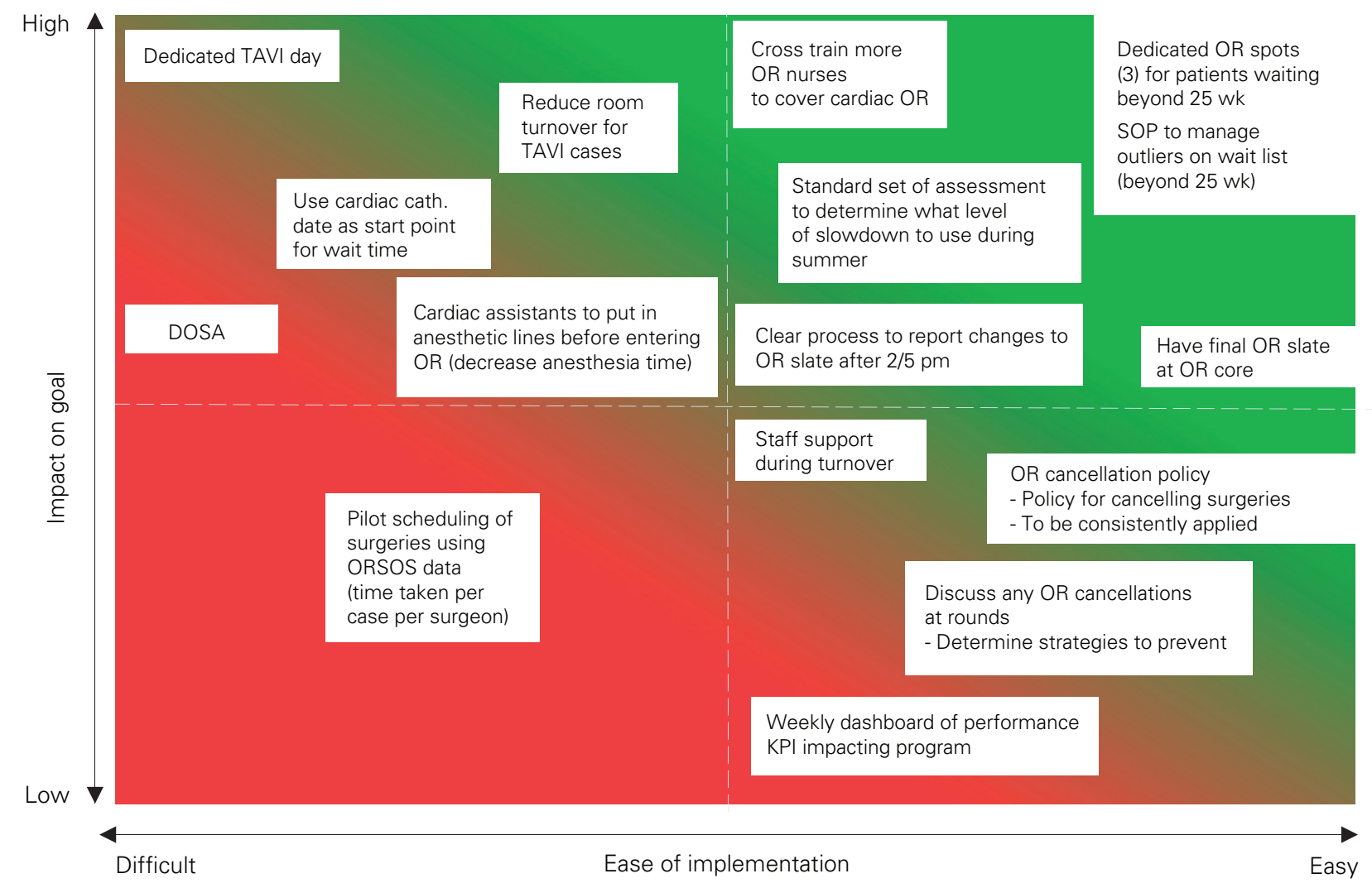

Fig. 1. Impact-effort analysis for operating room optimization. During the 5-day Kaizen (rapid improvement) workshop, individual projects were listed in each box and placed within the impact-effort analysis matrix on the basis of feedback from stakeholders. Cath = catheterization; DOSA = day of surgery admission; KPI = key performance indicator; OR = operating room; ORSOS = OR statistical operating system; SOP = standard operating procedure; TAVI = transcatheter aortic valve implantation. 
dedicated project manager, and Horizon Health Network assigned a process improvement facilitator. Through Horizon Health Network's decision support department and the NBHC, metrics were collected on the impact on key performance indicators and on ROI; these data were regularly analyzed and reported back to the team leaders and steering committee. It is important to note that during the study no additional hospital beds, OR theatres or physician resources were added. A weekly dashboard was created to monitor and facilitate improvement efforts (Fig. 2).

\section{Listing for surgery}

During the study, patients were stratified on the basis of urgency, as per the standard approach used at the NBHC. All patients considered for cardiac surgery were assessed by the surgeon on call and a consensus between cardiologist and surgeon was reached on the best treatment strategy. For more complex cases, patient flow and issues affecting flow were discussed at a weekly multidisciplinary conference where representatives of clinical cardiology, interventional cardiology and cardiac surgery are present and serve as the "Heart Team." Urgency was determined on an individual basis, but patients were assigned to 1 of 3 categories: urgent (for patients requiring surgery within $24 \mathrm{~h}$ ), in-hospital urgent (for patients requiring surgery within $7 \mathrm{~d}$ of assessment) and outpatient surgery (for patients able to be discharged home before their surgery). Patients in the outpatient surgery category were further stratified into semiurgent and urgent outpatient groups on the basis of the risk of waiting perceived by the individual surgeon at the time of consultation. The cardiac surgery wait list is managed and maintained by 2 NBHC access managers. The patient access manager establishes and maintains a coordinated approach to the management of patients waiting for surgery with the goal of improving access and providing information regarding patient wait times. As well, the access manager interprets the data in a way that is meaningful to the stakeholders, to help them understand current surgical issues, while ensuring the information meets quality standards for accuracy and timeliness.

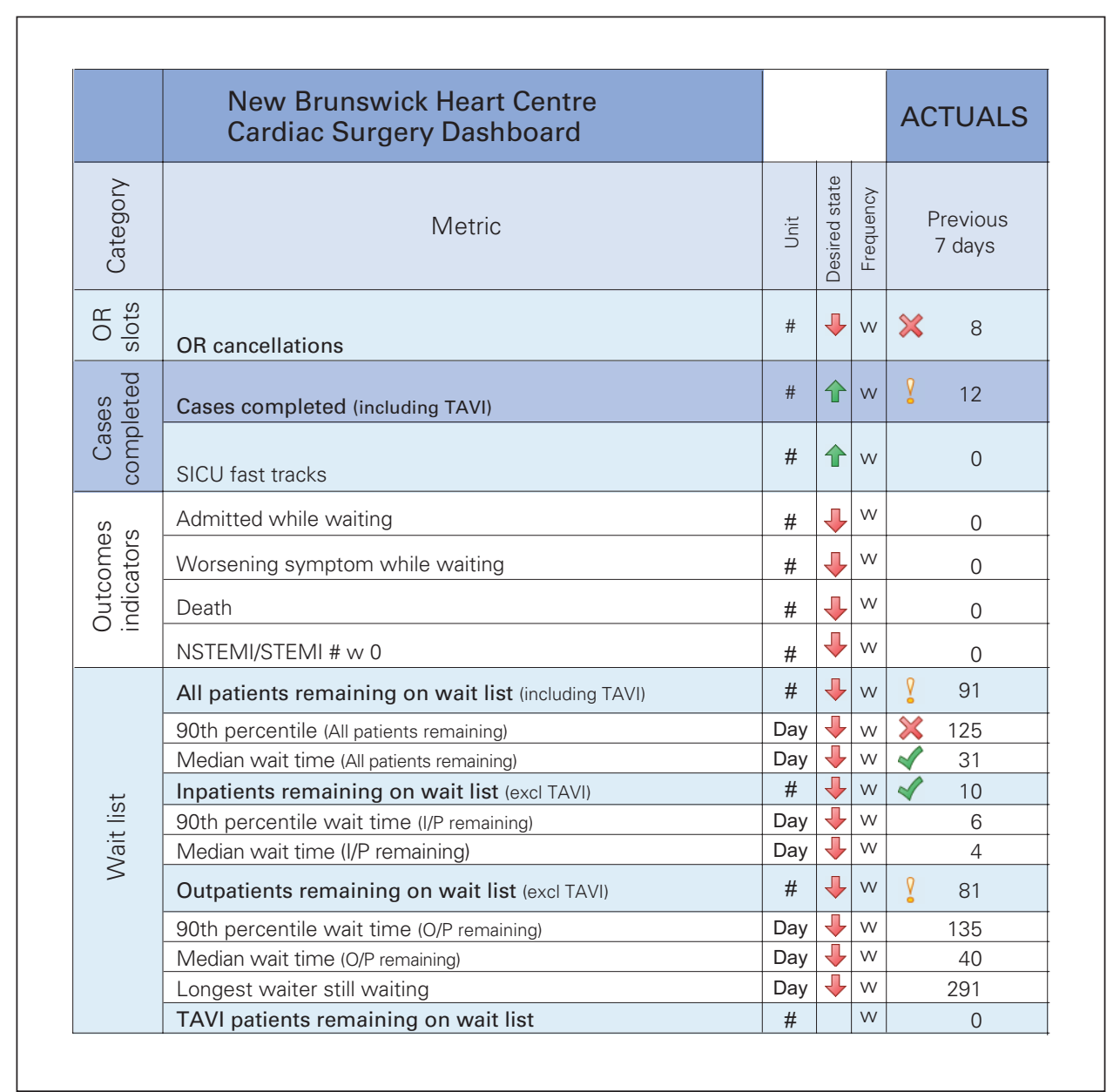

Fig. 2. Sample weekly dashboard. I/P = inpatients; NSTEMI = non-ST-elevation myocardial infarction; O/P = outpatients; OR = operating room; SICU = surgical intensive care unit; STEMI = ST-elevation myocardial infarction; TAVI = transcatheter aortic valve implantation; $w=$ week.

\section{Fast-track protocol}

The standard of care at the outset of the study was that all patients undergoing cardiac surgical intervention were admitted to a dedicated SICU bed after their surgery. In select cases identified by the surgeon, patients could be fast-tracked, which meant that they were eligible to be transferred to a stepdown unit as early as 4 hours after admission to the SICU. Fast-tracking of patients was in place at the NBHC for several years before the study in an attempt to optimize the use of the limited number of ICU beds. Patients who were eligible for fast-tracking were those who could breathe spontaneously, who did not require inotropes other than low-dose dopamine (maximum of $5 \mathrm{mg} / \mathrm{kg} / \mathrm{min}$ ) and who were believed to be otherwise stable.

\section{Cancellations}

A case was considered cancelled when a new procedure could not be performed as 
scheduled. The reason for cancellation was recorded and classified into 1 of the following categories: ICU bed or staff resource, floor bed or staff resource, OR staff resource, or surgeon related, which included situations in which the first procedure ran too long to allow a second procedure to be performed.

\section{Discharge and follow-up}

The care of all patients after surgery, including care in the ICU, was the responsibility of each individual surgeon. Generally speaking, all patients received antiplatelet therapy early (within $7 \mathrm{~h}$ of surgery), $\beta$-blockade to limit the risk of atrial fibrillation, statin therapy, and therapy with angiotensin converting enzyme inhibitors or angiotensin receptor blockers when indicated. The aim was to discharge patients within around 4 to 5 days after surgery, with mobility and independence being the main criteria for safe discharge.

\section{Results}

\section{Case volume}

Cardiac surgical volume at the NBHC remained relatively stable from $2009(n=753)$ to $2016(n=788)$, with small increases in some years (Fig. 3). This relatively stable level of clinical activity occurred in the setting of limited OR capacity (2 dedicated cardiac surgery rooms per day) and a dedicated ICU bed capacity of only 4 beds specifically assigned to cardiac surgery within a larger ICU. It should be noted that the opportunity exists to borrow additional ICU beds depending on availability and/or staff. Increased demands for cardiac surgery services resulted in a wait list

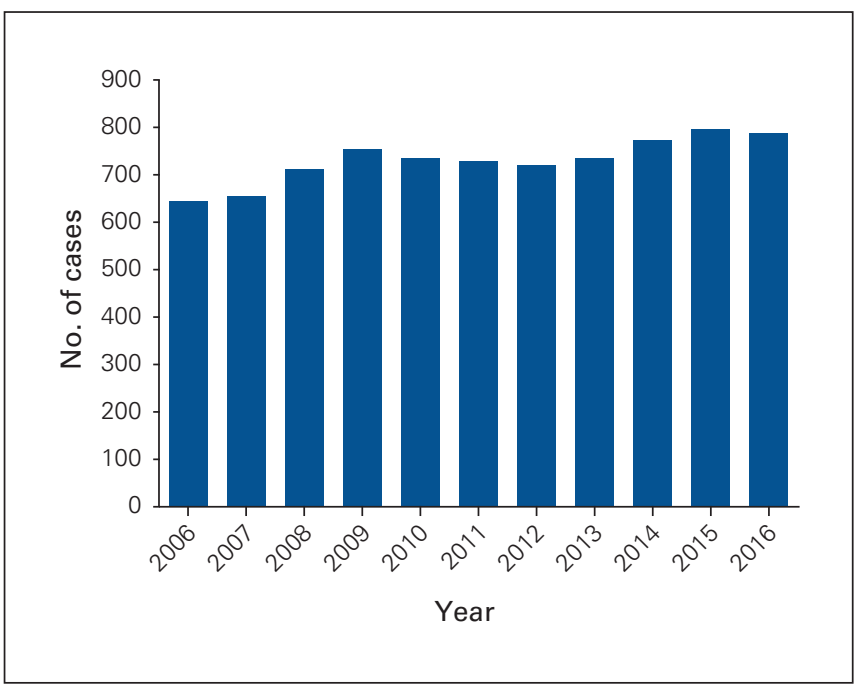

Fig. 3. Annual volume of cardiac surgery cases, including transcatheter aortic valve implantation, from 2006 to 2016 at the New Brunswick Heart Centre. for cardiac surgery that exceeded 100 patients at the beginning of the study. This meant that some patients waited more than 6 months for surgery, substantially exceeding the wait time of 6 weeks in Canadian guidelines. ${ }^{5}$ Implementation of the partnership with IHS started in September 2016. The annual numbers of cases at baseline and in years 1 and 2 of the study are presented in Figure 4. The annual number of cardiac surgical interventions increased from 788 at baseline to 826 in year 1 and 873 in year 2, representing a $10.8 \%$ increase in capacity.

\section{Fast-tracking}

Although a fast-track strategy existed before implementation of the partnership with IHS, the NBHC was encouraged as part of the implementation to allow more patients meeting the fast-tracking criteria to be sent to the cardiac surgery step-down unit on the day of surgery. This strategy allowed for a given ICU bed to be used by more than 1 cardiac surgery patient in a single day. Before the implementation of the IHS partnership, on average $3 \%$ of patients were fast-tracked (unpublished data). This number increased substantially in both year 1 and year 2 of the project, reaching more than $13 \%$ of all patients (Fig. 5 and Table 1). In part, this increase in fast-tracking was the result of efforts to optimize TAVI procedures by limiting their invasiveness. TAVI optimization was an NBHC project done independently of IHS, but it followed a similar Lean model and involved the implementation of conscious sedation and a percutaneous approach for nearly all patients undergoing TAVI procedures. This also meant that patients now recovered after the procedure in the catheterization laboratory bay area instead of in the ICU, and patients therefore bypassed the ICU

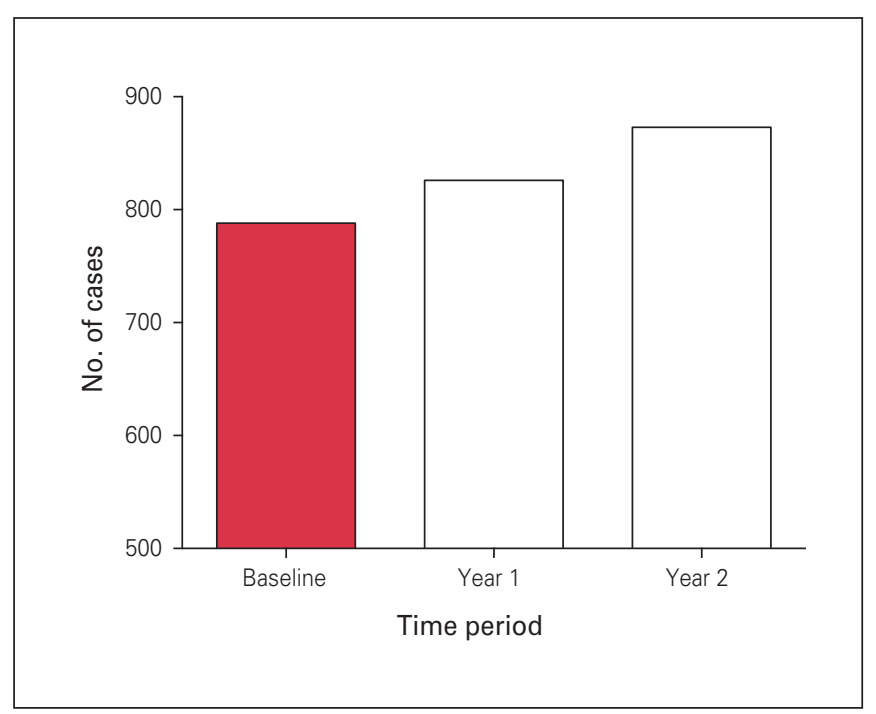

Fig. 4. Total number of cardiac surgical cases, including transcatheter aortic valve implantation, during the baseline year (the year before the implementation of the collobaration with Integrated Health Solutions) and years 1 and 2 of the collaboration. 


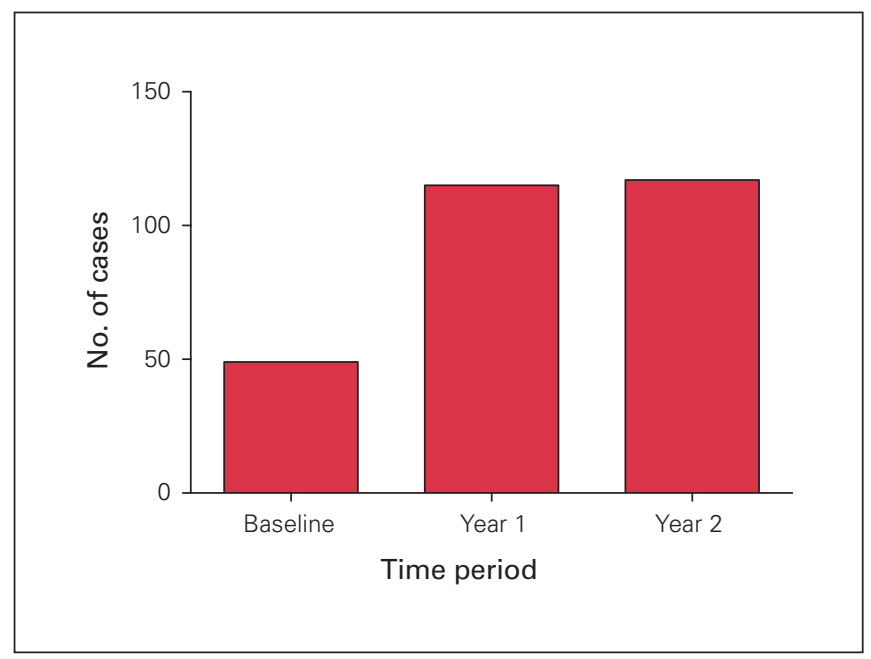

Fig. 5. Total number of patients who were fast-tracked.

\begin{tabular}{|c|c|c|c|}
\hline \multirow[b]{3}{*}{ Type of procedure } & \multicolumn{3}{|c|}{ No. (\%) of patients } \\
\hline & \multirow[b]{2}{*}{ Baseline } & \multicolumn{2}{|c|}{ NBHC-IHS partnership } \\
\hline & & Year 1 & Year 2 \\
\hline Percutaneous & $11(17)$ & $55(92)$ & $64(98)$ \\
\hline Conscious sedation & 0 & $19(32)$ & $60(92)$ \\
\hline
\end{tabular}

entirely (Fig. 4). These findings demonstrate that, within 2 years, TAVI procedures were being performed with conscious sedation (92\%) and a percutaneous approach $(98 \%)$ for nearly all patients. Patient discharge on day 1 did not occur before implementation of the IHS partnership; after 2 years of engagement, however, more than $60 \%$ of TAVI patients were being discharged the day after their procedure (unpublished data).

\section{Scheduling and listing for surgery}

All patients accepted for surgery were placed on a wait list for surgery as outlined earlier. Each of the 5 surgeons managed their individual wait list, but wait lists were also managed collectively to prevent patients from waiting too long, by finding opportunities to share patients. The IHS project allowed for additional agreements to be reached in an attempt to standardize listing criteria and sharing of patients who wait too long, to minimize discrepancies in wait times (Appendix 1, available at canjsurg.ca/007519 -a1). Over the study period, the best median wait time for patients was 35 days in the second year of the project (compared with 52 days). Similarly, the lowest 90th percentile wait time was 98 days in the second year of the project (compared with 126 days) (22\% reduction overall) (Fig. 6 and Table 2). The 90th percentile wait time is plotted over the duration of the study in Figure 6. Although Figure 6 illustrates substantial variability in wait

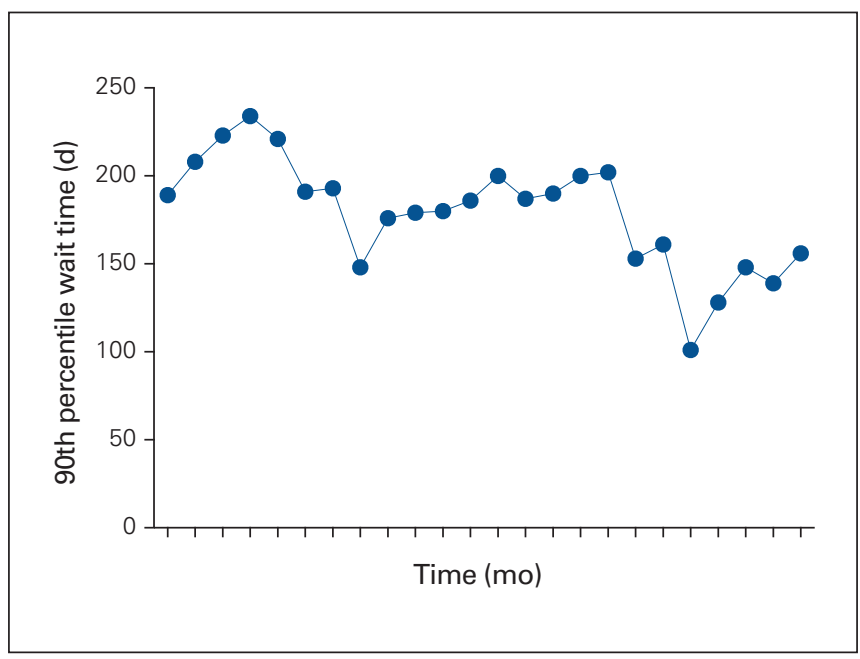

Fig. 6. Ninetieth percentile wait times for patients remaining on the wait list, calculated on a monthly basis during the study period.

times, it shows that there was an overall decrease in 90th percentile wait time during the study period. One should note that the overall number of patients waiting for surgery remained high during the study period, fluctuating between 80 and 150 patients. Despite these successes, challenges persisted: the number of OR cancellations increased to $7.5 \%$ of all cases despite the implementation of the IHS partnership, with limited ICU resources being the primary cause of cancellations (Fig. 7).

\section{Discussion}

The Canadian health care system is tasked with providing comprehensive care to all Canadians. Most of its funding comes from the public purse, and as such the health care system is dependent largely on government allocation., In the Canadian context, the role of industry in health care funding is often unclear. In fact, a partnership of health care institutions with industry is viewed by some as controversial. Recent white papers and major news stories on this subject highlight the controversy. We demonstrate in the present study that our experience with a partnership between clinicians and hospital administrators from the NBHC and industry in a Canadian environment was feasible and produced important benefits for patients.

The Kaizen methodology applied at the outset of the partnership resulted in strong engagement by all stakeholders, and they were able to identify and address a specific clinical problem: the long wait times at the NBHC for cardiac surgery. We describe in the present manuscript only a few of the multiple projects that were undertaken to target the wait time problem at the NBHC (illustrated in Fig. 1). The projects we outline were all initiated and championed by members of the care team, and together they resulted in substantial process changes in the cardiac surgical care system. Although it is difficult to demonstrate 


\begin{tabular}{|c|c|c|c|c|c|c|}
\hline \multirow[b]{3}{*}{ Metric } & & & \multicolumn{4}{|c|}{ NBHC-IHS partnership } \\
\hline & \multicolumn{2}{|c|}{$\begin{array}{l}\text { Baseline } \\
n=788\end{array}$} & \multicolumn{2}{|c|}{$\begin{array}{l}\text { Year } 1 \\
n=826\end{array}$} & \multicolumn{2}{|c|}{$\begin{array}{l}\text { Year } 2 \\
n=873\end{array}$} \\
\hline & Inpatient & Outpatient & Inpatient & Outpatient & Inpatient & Outpatient \\
\hline Median wait time, $d$ & 4 & 52 & 5 & 64 & 5 & 35 \\
\hline $90^{\text {th }}$ percentile wait time, $\mathrm{d}$ & 7 & 126 & 8 & 140 & 8 & 98 \\
\hline $\begin{array}{l}\text { Patients whose wait time was within CCS } \\
\text { guidelines, } \%\end{array}$ & 74 & 25 & 92 & 19 & 85 & 47 \\
\hline
\end{tabular}

a cause-and-effect relationship, we believe that we were able to ultimately increase the number of surgical interventions yearly over a 2 -year period (total increase of $10.8 \%$ ) without specifically increasing resources. The OR resources remained at 2 rooms per day during the week with a target number of 18 surgeries per week during regular hours excluding holidays. Our findings illustrate that effective solutions can be found in a managed care environment where resources are limited. Solutions were identified by the participating stakeholders, implemented and shown to improve surgical capacity. We acknowledge that our success was highly dependent on the people involved, their engagement and their capacity to identify opportunities and finds ways to institute lasting changes.

One of the most important bottlenecks we identified early on was our limited ICU capacity because of a limited number of beds. The approach we eventually chose was therefore to maximize our ability to bypass the ICU (when feasible) and to minimize the time each patient spent in the ICU (fast-tracking). To achieve this, we reviewed the process of care for TAVI, which, at the time, required admission to the ICU. After our review, we decided that a number of changes were possible, such as the implementation of conscious sedation, using a percutaneous approach, and use of the cardiac catheterization bay area rather than the

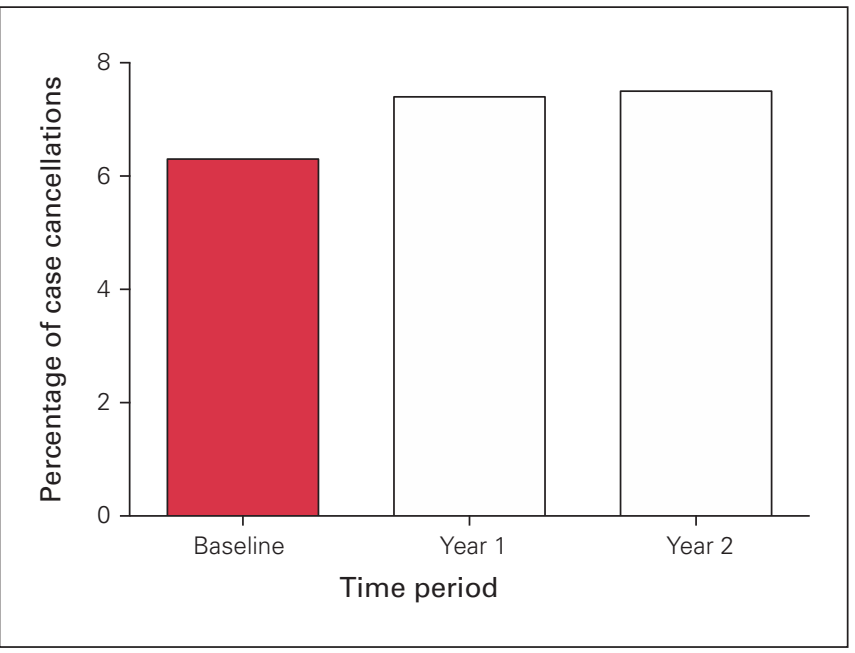

Fig. 7. Percentage of case cancellations.
ICU for recovery. Within a few months, we were able to implement these changes, resulting in the majority (> 95\%) of TAVI cases being performed with minimal intervention, the ICU being bypassed and patients being discharged on day 1 after their intervention. Similarly, we identified our fast-track protocols as a way to optimize use of our ICU beds. Fast-tract protocols had been in place for years at the NBHC to allow patients to be transferred out of the ICU to a step-down unit on the floor within a few hours after cardiac surgery. However, fast-tracking was only being used for $3 \%$ of patients before our intervention. We sought to identify standard criteria for eligibility, which were agreed upon and implemented, resulting in a 4-fold increase in the number of patients fast-tracked during our study period. This meant that during our study period we increased the number of fast-tracked patients from fewer than 50 to nearly 120 per year (less than half had undergone TAVI). Although, again it is difficult to directly prove a causal relationship, we believe that the approach we undertook was safe in selected patients, substantially limited the overall utilization of the ICU resource and contributed to the overall increase in capacity we saw.

The increased OR capacity resulted in some relief for patients waiting for surgery. We were able to improve the median wait time and, in particular, our 90th percentile wait time, which is a very sensitive measure of the severity of wait times. Nearly $50 \%$ of outpatients now wait within the recommended wait times, as compared with $25 \%$ before our changes. However, the total number of patients waiting for surgery did not consistently decrease during the study period and has remained between 80 and 150 patients, suggesting that most of our efforts affected efficiency (wait times), not the number of referrals, which remains high. We also standardized our approach to creating the surgery lists, categorizing the list by urgency and, if necessary, sharing patients among surgeons if the patients had waited for a longer time than acceptable (Appendix 1). Discussion among surgeons is ongoing to continue to improve access and ensure fairness for all patients. Although we have not reached the point where a common list of patients is shared, all efforts are being made to ensure that the patients with the most urgent 
conditions undergo surgery first. Substantial efforts were also undertaken on the cardiac surgery floor to ensure that no additional bottlenecks would be created by the increased capacity. This meant that the entire process of care was reviewed, and efforts were made as part of the IHS partnership to address early rounds, early discharge, discharge pathways and the day of surgery admission (DOSA) program. All these efforts were aligned to limit cardiac surgery bed utilization in support of the changes aimed at increasing the number of interventions performed. We acknowledge that should we be able to sufficiently increase capacity at the ICU level, we would probably then face new bottlenecks that could prevent timely discharge from our cardiac ward.

To the best of our knowledge, we are the first program in Canada to have engaged in this manner with the IHS specifically targeting the deliverity of cardiac surgery care. Some literature looking at this type of approach in surgery supports our findings, but overall the experience is limited. ${ }^{9-11}$ Our findings provide some insight into the potential value of industry partnership in addressing a common problem in the Canadian health care system. It should be noted that the present study focused largely on the clinical implementation of the program and its results. Clinicians were not obliged to use specific products - they retained full autonomy to decide which procedures were indicated for which patients and to decide which medical devices from which companies to use.

\section{Limitations}

Our study provides only a 2-year snapshot of the cardiac surgery service at the NBHC. Furthermore, it is evident that the assesssment of overall surgical capacity is complex and involves multiple aspects of a patient's journey within the health care system, which were not reviewed in detail in the present study. We also acknowledge that we have made the case that our increased capacity was directly linked to our IHS project and its implementation. The clear temporal relationship and sustained findings over the 2-year period support this view. It was also very clear during the process that the stakeholders' engagement and commitment to the process was 1 of the main factors responsible for the successes we have enjoyed. The present study illustrates that identifying problems and finding solutions is a process that needs to come from within, per the Kaizen philosophy. With the Kaizen methodology and the approach taken by IHS, all problems and solutions were worked out within each working group; the consultants were there mainly to provide structure, maintain timelines and ensure accountability of those involved. Health care delivery is complex and involves a number of systems with multiple players, all with competing interests. It was beyond the scope of this article to speculate on all aspects of care delivery. We also acknowledge that our study was largely observational, but it does offer important insights and evidence that process of care efficiencies exist and need to be explored as part of all improvement initiatives before additional resources are assigned to solve care deficiencies. Furthermore, we provide evidence that partnership with industry is possible and potentially requires payers to look beyond the lowest cost possible as the primary goal of any interaction with industry for additional benefits. It is evident from our study that industry partners may be able to provide, albeit at some cost, substantial added value beyond the sale of specific products. Added value can be hard to define and may vary from institution to institution. Aspects to take into consideration could include product services, technical expertise, recall protections, databases, clinical outcomes registry support and patient follow-up infrastructure, which are not covered by the health care system by and large. In our case, the added value created by the relationship between the NBHC and industry was around the Kaizen expertise, access to health care experts with international exposure to tertiary cardiology services, and mentorship to identify solutions to the NBHC's wait list problem. We acknowledge that other institutional resources may be available (institution dependent) and could have provided similar results or improvements. Our study was not designed to compare institutional versus contractual partnership.

\section{Conclusion}

The partnership between the NBHC and IHS promoted team cohesiveness and led to substantial reorganization and realignment of efforts to limit wait times and substantially increase the NBHC's cardiac surgical capacity over a 2-year period.

Affiliations: From the New Brunswick Heart Centre, Saint John, N.B. (Watling, Doucet, Hassan, Lutchmedial, Macleod, Pozeg, Brown, Légaré); and Medtronic Canada, Mississauga, Ont. (Zohrabi, Fedirko).

Competing interests: This study reports the results of a partnership between the New Brunswick Heart Centre and Integrated Health Solutions (IHS), which is a service produced by Medtronic Canada. M. Zohrabi and J. Fedirko were members of the IHS team. Their primary role as authors was to ensure that the IHS process was described accurately in the article. No other competing interests were declared.

Contributors: J.-F. Légaré designed the study. A. Watling, J. Doucet, M. Zohrabi, J. Fedirko, J. MacLeod and J.-F. Légaré acquired the data, which A. Watling, J. Doucet, J. Fedirko, A. Hassan, S. Lutchmedial, J. MacLeod, A. Pozeg, C. Brown and J.-F. Légaré analyzed. A. Hassan, S. Lutchmedial and J.-F. Légaré wrote the manuscript, which A. Watling, J. Doucet, M. Zohrabi, J. Fedirko, S. Lutchmedial, J. MacLeod, Z. Pozeg, C. Brown and J.-F. Légaré critically revised. All authors gave final approval of the version of the article to be published.

\section{References}

1. Canadian Institute for Health Information. National health expenditure trends, 1975 to 2019. Ottawa: Canadian Institute for Health Information; 2019. Available: https://www.cihi.ca/en/health-spending

2. Rosvall BR, Forgie K, MacLeod JB, et al. Impact of obesity on intensive care unit resource utilization after cardiac operations. Ann Thorac Surg 2017;104:2009-15. 
3. Soril LJJ, Adams T, Phipps-Taylor M, et al. Is Canadian healthcare affordable? A comparative analysis of the Canadian healthcare system from 2004 to 2014. Healthc Policy 2017;13:43-58.

4. Hall W, Smith N, Mitton C, et al. Assessing and improving performance: a longitudinal evaluation of priority setting and resource allocation in a Canadian health region. Int 7 Health Policy Manag 2018;7:328-35.

5. Legare J-F, Li D, Buth KJ. How established wait time benchmarks significantly underestimate total wait times for cardiac surgery. Can 7 Cardiol 2010;26:e17-21.

6. O'Neill BJ, Simpson CS; Canadian Cardiovascular Society Access to Care Working Group. The politicization of the wait times issue and how to rise above it. Can 7 Cardiol 2008;24:113.
7. Tucker ME. Rooms with a view: Kaizen events put things in their proper place. OR Manager 2014;30:14-6,21.

8. Wennecke G. Kaizen-LEAN in a week: how to implement improvements in healthcare settings within a week. MLO Med Lab Obs 2008;40:28, 30-1.

9. Blouin-Delisle CH, Drolet R, Gagnon S, et al. Improving flow in the OR. Int 7 Health Care Qual Assur 2018;31:150-61.

10. Iannettoni MD, Lynch WR, Parekh KR, et al. Kaizen method for esophagectomy patients: improved quality control, outcomes, and decreased costs. Ann Thorac Surg 2011;91:1011-7, discussion 1017-8.

11. Mason SE, Nicolay CR, Darzi A. The use of Lean and Six Sigma methodologies in surgery: a systematic review. Surgeon 2015;13:91-100. 